\title{
Research on Comprehensive Training Platform for Software Engineering Based on Android
}

\author{
Pan Chunhua \\ School of Computer \\ Qinghai University for Nationalities \\ Xining City, Qinghai Province \\ e-mail: 155091145@qq.com \\ Sun Yan \\ School of Computer \\ Qinghai University for Nationalities \\ Xining City, Qinghai Province \\ e-mail: sy0623@163.com
}

\author{
Zan Fengbiao \\ School of Computer \\ Qinghai University for Nationalities \\ Xining City, Qinghai Province \\ e-mail: 835420632@qq.com
}

\begin{abstract}
With respect to the training program of software engineering specialty, this paper puts forward the comprehensive training platform of Chinese character dictation competition based on Android, and clarifies the purpose and main contents of the comprehensive training platform. Based on the hardware and software facilities of the campus, the C / S model training platform, the use of Android integrated training platform to achieve the Chinese character writing, clearing, timing and other functions, managers of the entire process of the game management, including the participating teams and players, the administrator can simultaneously obtain the client input Chinese characters, and display on the big screen, the judges then give the results after the score and statistical display. The whole integrated training platform is light and practical.
\end{abstract}

\section{Keywords-C/S; Server; Client APP}

\section{INTRODUCTION}

Software is applied in many aspects in modern society. Almost all industries have computer software applications, such as manufacturing, agriculture, banking, aviation, government agencies. Modern life is almost inseparable from mobile phone. Mobile applications are deployed in an incredible pace. These applications not only promote economic and social growth, but also improve the efficiency of work and life in general. The mainstream mobile phone operating systems include Android, IOS and, WP. With the building of training platform on Android system, software engineering professionals would cultivate their software analysis, design, development and maintenance capabilities, as well as skills in project organization \& management, teamwork, technological innovation \& market development. This provides good experimental teaching innovation in practical environment, and reform new ideas in the process.

\section{SKILLED REQUIRED FOR SOFTWARE ENGINEERING PROFESSIONALS}

Software engineering students need to learn discrete mathematics, object-oriented programming, data structure, data communication \& computer network, database integrated-platform principle, software engineering, computer integrated-platform structure, software project management, unified modeling language, software quality and testing. Through a comprehensive training platform students can master the mainstream and the typical software development and debugging capabilities, understand the status of software engineering development and trends, acquire good communication skills and positive teamwork attitude.

\section{INTEGRATED TRAINING PLATFORM FEATURES AND CONTENT}

Software engineering professionals need to drive the theory, practice, network and experimental teaching as a whole, and complete the three-dimensional teaching as a complete teaching organization model.

The comprehensive training platform is based on software engineering development practice:

1) To build a unified mainstream software technology, the standard is based on the C / S architecture of the integrated training platform;

2) Android-based APP is to imitate the training platform of the CCTV Chinese character dictation competition. The specific function is to provide students a Chinese characters interface to write and to submit the results. The server side allows the administrator to record the student's message and question, correct and send the answers, and summarize personal performance and team results, and finally show the result rankings. 


\section{P ANDROID-BASED TRAINING PLATFORM}

\section{A. Training platform system design}

The integrated training platform hardware requirement: A desktop computer installed with Windows and a Tablet PC installed Android system. This setup is simple and easy to operate, with a strong practical and promotional value. Software development system requires Java programming JDK and a variety of IDE (Eclipse or Netbeans environment), and database software (such as the commonly used Excel and access database, SQL Server 2005). The software for the entire training platform is common, easy to use, and reliable.

\section{B. Training platform architectural framework}

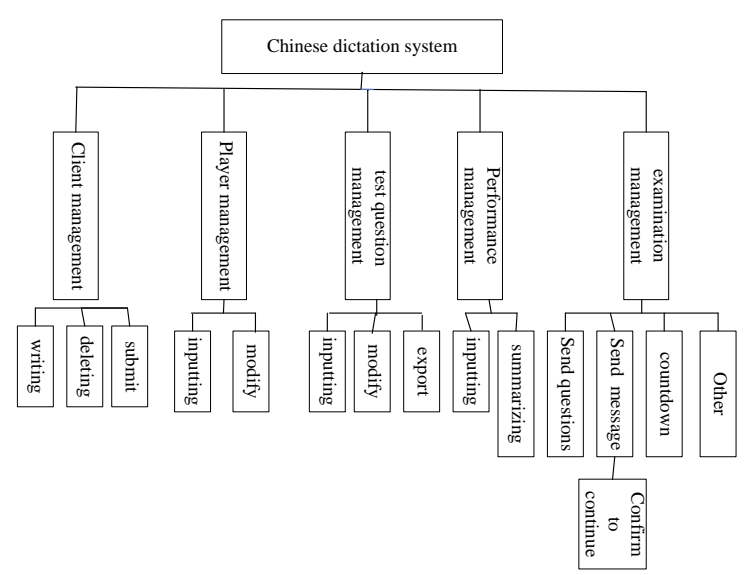

Figure 1. Software Structure Diagram

Modern computer science mathematical based graph theory, research shows that the structure determines the nature. The architecture of the training platform is also a hierarchical structure of the tree. Based on the C / S model two-tier model: the client + server (server program + database program). Results also shows, by the training platform architecture allows students to fully grasp software engineering's required skills.

\section{1) Client App program}

The client uses the countdown display control and input pen to write the required Chinese characters, complete the writing and modify the Chinese characters, submit the result, and then wait for the server to judge. as shown in Figure 2.

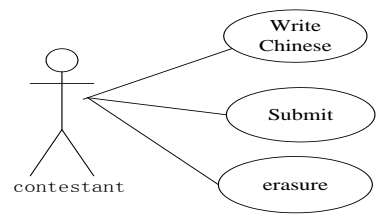

Figure 2. Client-side structure

2) Server-side manages the entire process of the competition

Record the team and team members information, access client input Chinese characters and display on the big screen, server controls the time of competition, show the correct answer after the client completed the submission. The judges give the points and calculate the result of the competition. The structure is shown in Figure 3.

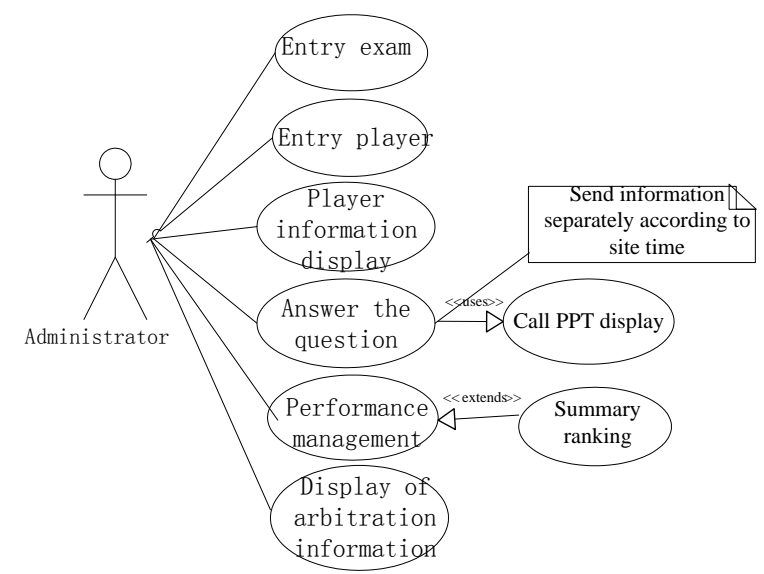

Figure 3. Server-side Structure

3) Module functions

- The client input: Students input words on the grid, complete the deletion of the whole word or erase a stroke, confirm the submission

- Player information: Enter the modified unit, name information.

- Test results management: Use ACCESSS database and Excel as a database with statistical support. Complete the entry, modify the questions and perform statistic functions.

- Test management: Send the beginning of the test information, questions, time information, arbitration information, send the arbitration officer.

4) Network communication module

Network communication concept and skillset is a weakness for many software engineering students. Understand and master the network architecture and communication model is the key to address this problem. This is the core part of the training platform. The end system in Figure 4 is the PC, mobile phones and other entities in the communication application process. The relay system is a router with routing and packet forwarding function. The development of network communication process based on Android system needs to have a bridge-like abstract unit connected to the application process. In the Android system, we can use the existing Socket class to complete, and the interface Socket in the TCP / IP architecture is located in the Application Layer and Transport Layer, as shown in Figure 5. From the figure if there is no interface, the entire communication will not be able to proceed; it is like we cannot send mail without postman. To understand the network structure specifically, students need to start from the horizontal peer-to-peer communication and the vertical direction of the actual data transfer. Understanding both the horizontal and the vertical levels of communication is difficult. The system training platform uses the TCP connection and socket interface to complete the underlying 
communication, achieving the correct timing and answer transmission with the send and receive functions. Students through the Android based training platform can experience a specific communication process.

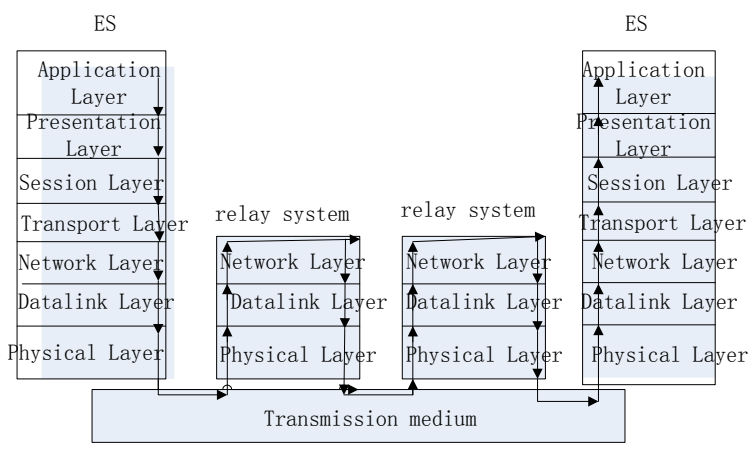

Figure 4. Network OSI Reference Model

\begin{tabular}{|c|c|c|}
\hline $\begin{array}{l}\text { Application } \\
\text { Layer }\end{array}$ & FTP、TELNET、HTTP、DNS & SNMP、TFTP、NTP、DNS \\
\hline \multicolumn{3}{|c|}{ socket } \\
\hline $\begin{array}{c}\text { Transport } \\
\text { Layer }\end{array}$ & \multirow[t]{2}{*}{ TCP } & UDP \\
\hline $\begin{array}{l}\text { Layc1 } \\
\text { Letwork } \\
\text { Layer }\end{array}$ & & \\
\hline $\begin{array}{l}\text { The host to the } \\
\text { network layer }\end{array}$ & \multicolumn{2}{|c|}{ Network access layer } \\
\hline
\end{tabular}

Figure 5. TCP/IP Architecture

A particular communication process: The Server first starts the service, the establishment of SOCKET and begins to listen to the state and waits to connect, and start the service. The Client press the start button, set the client writing time and other display information. The Client enters into the connection state, the Client answers. After entering the answer and establish a connection with the Server, the answer is sent to the Server-side.

5) Complete class diagram of the integrated training platform design

The comprehensive training platform design and development uses the currently popular object-oriented approach. The design of the class and the various types of functional methods are: The boot interface Start, write interface class HztxView, write control class Hztx, and internal class (answer list class DatiListener, end of the answer list class JieshuListener, timing class MyCount), writing action classes MyAction and subclasses (writing class MyPath and erase class MyEraser), etc. ...

6) Timing statistics function

When the PC server sends a start entering command, the Android client counts down based on the received time and displays the correct answer at the end of the time for the judges and the audience to end the competition. The server can view all teams and player scores and rankings, and to send the required information to the client.

\section{CONCLUSION}

Writing Chinese characters is the transmission of Chinese civilization, enhance the understanding of Chinese culture, and increase the love of our country. The development of the integrated training platform for writing Chinese characters provides a good platform with good social benefits. The comprehensive training platform for Chinese character dictation competition exceeds the basic requirements of school Chinese characters. To process information and the final score and display on the big screen for the judges and the audience in public places for judgments meets the requirement of fairness for the competition. Through the training platform to create a way for students to take the initiative, self-learning environment, students can systematically master the basic knowledge of software engineering and software development of the whole process; train software engineering students other comprehensive ability, easy to use, functional software for the professional, to provide a complete, actual, open and simulated training integrated network platform.

\section{ACKNOWLEDGMENT}

Project support: Ministry of Education "Chunhui plan" cooperation research project 2015 project, project number: Z2015053

\section{REFERENCES}

[1] Chinese character dictation conference, official website http://tingxie.cntv.cn/

[2] Wood grain. A cultural reflection from "dictation" [J]. Trade unions, 2013: 9.

[3] Li Jiake .Android comprehensive training platform analysis and development. Lanzhou Jiaotong University master's degree thesis, 2014

[4] Zhang Shicheng. Based on Google Android platform application development and research [J]. Computer Knowledge and Technology, 2009 (28): 31-32.

[5] Yang Fengsheng .Android application development Secret [M] Beijing: Machinery Industry Press, 2011: 40-52.

[6] He Baohong. From the fixed Internet to the mobile Internet [J]. Information and Communication Technology, 2010 (4): 54-58.

[7] In-Stat.3G Internet applications will usher in blowout [J]. Weekly Computer News, 2008 (22): 26-27. Article in a conference proceedings.

[8] H. Goto, Y. Hasegawa, and M. Tanaka, "Efficient Scheduling Focusing on the Duality of MPL Representatives," Proc. IEEE Symp. Computational Intelligence in Scheduling (SCIS 07), IEEE Press, Dec. 2007, pp. 57-64, doi:10.1109/SCIS.2007.357670. 